\title{
Prompt surgery is effective for acute type A aortic dissection with cerebral ischemia
}

\author{
Yunxing Xue $\mathrm{e}^{1,2,3 \#}$, Xinlong Tang ${ }_{1,2,3 \#}^{1,2,3}$, Xiyu Zhu ${ }^{1,2,3 \#}$, Yuzhou $\mathrm{Lu}^{1,2,3}$, He Zhang ${ }^{1,2,3}$, Wei Xie ${ }^{1,2,3}$, \\ Qing Zhou ${ }^{1,2,3}$, Dongjin Wang ${ }^{1,2,3}$
}

${ }^{1}$ Nanjing Drum Tower Hospital Clinical College of Nanjing Medical University, Nanjing, China; ${ }^{2}$ Department of Thoracic and Cardiovascular Surgery, the Affiliated Drum Tower Hospital of Nanjing University Medical School, Nanjing, China; ${ }^{3}$ Institute of Cardiothoracic Vascular Disease, Nanjing University, Nanjing, China

Contributions: (I) Conception and design: Y Xue; (II) Administrative support: Q Zhou, D Wang; (III) Provision of study materials or patients: X Tang, X Zhu; (IV) Collection and assembly of data: Y Lu, H Zhang, W Xie; (V) Data analysis and interpretation: Y Xue, X Tang; (VI) Manuscript writing: All authors; (VII) Final approval of manuscript: All authors.

\#These authors contributed equally to this work.

Correspondence to: Dongjin Wang, MD. 321 Zhongshan Road, Nanjing 210000, China. Email: dongjinwang_gl@163.com.

\begin{abstract}
Background: Acute type A aortic dissection (aTAAD) with preoperative cerebral ischemia (CI) is common and lethal, but the timing and treatment method remain uncertain. We retrospectively reviewed our aTAAD patients with $\mathrm{CI}$ and analyzed the outcomes and related risk factors.

Methods: From January 2011 to December 2019, 1,173 patients diagnosed with aTAAD from Nanjing Drum Tower Hospital were enrolled. Among them, 131 patients had CI preoperatively (CI group), and 1,042 patients were in the non-CI group. One hundred eight in the CI group and 984 in the non-CI group received central repair surgery. Fifteen patients had postoperative cerebral complications (CC) and 93 had non-CCs. ROC curves were used to identify the safe duration of preoperative CI.

Results: The CI group was older (56.3 vs. 53.2 years, $\mathrm{P}=0.013$ ) and had lower rates of pain, chest pain and back pain $(77.9 \%$ vs. $94.4 \%$, $75.4 \%$ vs. $87.5 \%$ and $30.8 \%$ vs. $42.3 \%$, respectively) than the non-CI group. The CI group had a higher rate of preoperative hypotension and tamponade $(13.7 \%$ vs. 6.0\%, $26.9 \%$ vs. $10.4 \%$, respectively; $\mathrm{P}=0.000$ ). More patients in the $\mathrm{CI}$ group did not receive central repair surgery, and the CI had higher mortality (28.2\% vs. $15.9 \%)$. CI without central repair surgery was a strong risk factor for mortality. CI patients with CC after central repair had a higher mortality, and preoperative coma was the strongest risk factor for postoperative CC.A duration between CI symptoms and central repair surgery of less than 12.75 hours is recommended.
\end{abstract}

Conclusions: Prompt surgery is effective for aTAAD with CI, and preoperative coma and a safe duration longer than 12.75 hours would predict worse outcomes.

Keywords: Aortic dissection; cerebral ischemia (CI); surgery

Submitted Jul 01, 2020. Accepted for publication Dec 25, 2020.

doi: $10.21037 /$ jtd-20-2349

View this article at: http://dx.doi.org/10.21037/jtd-20-2349

\section{Introduction}

Cerebral ischemia (CI) is a common comorbidity in aTAAD patients. The prevalence rate is $15.1 \%$ according to newly reported data from the International Registry of Acute Aortic Dissection (IRAD) (1), which is higher than the previously reported rate of $6 \%(2,3)$. Thus, patients with CI have a significantly higher mortality rate of $25.7-40.2 \%$ than the cohort without CI at $12.0-22.7 \%$. Additionally, patients with preoperative CI had a lower rate of central repair, and more postoperative complications. Although central repair surgery can be performed in patients with CI with acceptable 


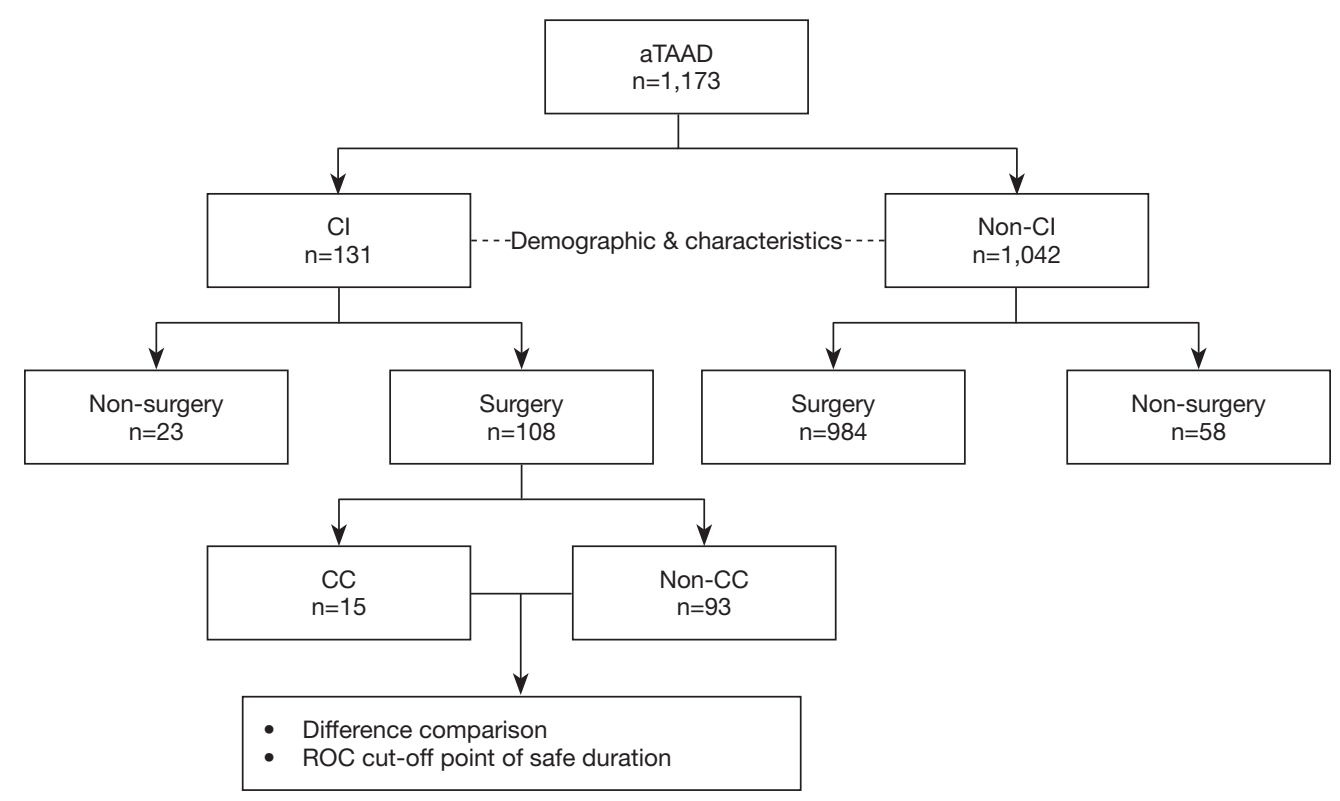

Figure 1 Flowchart of the research.

mortality, the increased mortality and incomplete recovery of brain injuries make the timing and method of surgery a huge challenge. We analyzed the characteristics of CI patients, effective role of central repair surgery and safe duration from CI symptoms onset to surgery. We aimed to propose a strategy for treating aTAAD patients with concomitant CI based on our single-center results.

We present the following article in accordance with the STROBE reporting checklist (available at http://dx.doi. org/10.21037/jtd-20-2349).

\section{Methods}

\section{Patients}

A retrospective cohort analysis was performed on patients presenting with aTAAD at Nanjing Drum Tower Hospital in China between January 2011 and December 2019. The institutional review board and ethics committees of hospital reviewed and approved the study. In total, 1,173 patients were divided into the CI $(n=131)$ and nonCI groups $(n=1,042)$. CI referred to neurological deficits confirmed by physical examination and radiological findings when patients visited our center. The symptoms of CI recovered before surgery were transient, and others were persistent. The CI and non-CI groups comprised 108 and 984 patients, respectively, who received open central repair surgery. Fifteen of the $108 \mathrm{CI}$ patients with surgery had postoperative cerebral complications (CC), and 93 had nonCC. CC were indicated as positive results from cranial CT or MRI, or global neurological deficits without awareness following discharge or death after surgery (Figure 1).

\section{Treatment strategy}

All the patients diagnosed with aTAAD were confirmed by computed tomography angiography (CTA) and transferred to the cardiovascular surgery intensive care unit. CI history and neurological physical examination were recorded by physicians. Patients with preoperative CI were advised to receive cranial CT or CTA checks. Central repair surgery was necessary and recommended for all the patients with CI. The reasons for not receiving open surgery were preoperative rupture, family refusal and comorbid diseases, such as CI. Three patients received intracranial angiography accompanied by basilar artery stent implantation first, one patient's consciousness recovered after the first stage and had undergone open central repair, and two others had no change in consciousness and had not received secondstage central repair. Central repair surgery involved proximal primary intimal tear resection and dissected aorta replacement; in some cases, we also inserted a stent in the aortic arch and descending aorta $(4,5)$. The root procedure included the Bentall procedure, root reconstruction and valve-sparing root replacement (6). 
The right axillary artery and femoral artery were the first choices for arterial cannulation. Based on the intended surgical procedure and cannulation sites, we used the cerebral perfusion approach. Intraoperative cerebral oxygen testing was used to assess the effectiveness of intraoperative cerebral perfusion. When the value was less than $20 \%$ of the baseline, we believed that cerebral perfusion was not sufficient, and additional measures were added for proper cerebral perfusion.

All the patients were sent for recovery in the intensive care unit postoperatively. Physicians assessed the patients' consciousness status every four hours, and emergency cranial CT was necessary if they did not wake after 12 hours.

The study was conducted in accordance with the Declaration of Helsinki (as revised in 2013). The current study was approved by the institutional review board of Nanjing Drum Tower Hospital (2020-185-01) and patient consent was waived due to the retrospective nature of this study.

\section{Statistical analysis}

All the data were presented as $\mathrm{n}$ (\%) for categorical variables and means \pm standard deviation for normally distributed continuous variables. Between-group differences were analyzed using $t$-test for continuous variables and a chi-squared or Fisher's exact test for categorical variables. Multivariate analysis was performed using a binary logistic regression model to discriminate independent risk factors for the 30-day mortality in the separated groups: whole group, CI group and surgical group. ROC curves were used to identify the safe duration of preoperative CI in the CI group. Data analysis was performed using SPSS 23 (IBM, Herrenberg, Germany). A P value of less than 0.05 was considered statistically significant.

\section{Results}

\section{Characteristics of patients in the CI group: compared with the non-CI group}

Compared with the non-CI group, the CI group was older $(56.3 \pm 13.4$ vs. $53.2 \pm 13.5$ years; $\mathrm{P}=0.013)$ and had fewer male patients $(69.5 \%$ vs. $75.4 \% ; \mathrm{P}=0.139)$. Patients in the CI group were transferred to the hospital more quickly from symptom onset $(8.4 \pm 6.0$ vs. $18.9 \pm 30.0$ hours; $\mathrm{P}=0.000)$. The CI group had a lower rate of pain symptoms $(77.9 \%$ vs. $94.4 \% ; \mathrm{P}=0.000)$, particularly in the chest $(75.4 \%$ vs. $87.5 \% ; \mathrm{P}=0.000)$ and back $(30.8 \%$ vs. $42.3 \% ; \mathrm{P}=0.012)$, but no differences in the abdominal and leg positions. The rates of hypertension (already diagnosed) and Marfan syndrome were similar between the two groups. The medical histories were also similar. Fewer patients had a smoking history ( $14.5 \%$ vs. $23.4 \% ; \mathrm{P}=0.021)$ in the CI group and nearly the same trend for alcohol use $(9.2 \%$ vs. $15.4 \% ; \mathrm{P}=0.059)$. Preoperative organ ischemia of the limb, mesenteric and myocardial were nearly similar, but more patients in the CI group had preoperative hypotension $(13.7 \%$ vs. $6.0 \%$; $\mathrm{P}=0.000)$ and tamponade $(26.9 \%$ vs. $10.4 \% ; \mathrm{P}=0.000)$. Fewer patients in the CI group had finally received open surgery finally $(82.4 \%$ vs. $94.4 \% ; \mathrm{P}=0.000)$, and the mortality was significantly higher than that in the non-CI group (28.2\% vs. $15.9 \% ; \mathrm{P}=0.000)$ (Table 1). No differences were found in either method regarding the root procedure or total arch replacement (44.4\% vs. $47.5 \% ; \mathrm{P}=0.551)$. The methods for cerebral perfusion in the two groups were the same distribution, and most of patients received antegrade cerebral perfusion $(79.7 \%$ vs. $82.0 \% ; \mathrm{P}=0.540)$.

\section{Risk factors for death in the whole group, CI group and surgical group}

Preoperative CI was not a risk factor for death in either the whole group (OR: $1.273 ; 95 \% \mathrm{CI}: 0.742-2.184 ; \mathrm{P}=0.381$ ) or surgical group (OR: 0.794; 95\% CI: 0.462-1.364; $\mathrm{P}=0.403$ ). Older age was a risk factor for death in the three groups, particularly in individuals older than 70 years. Tamponade was a risk factor in the whole group (OR: $2.799 ; 95 \%$ CI: 1.785-4.391; $\mathrm{P}=0.000)$ and surgical group (OR: 2.853; $95 \%$ CI: $1.837-4.431 ; \mathrm{P}=0.000)$ but not in the CI group (OR: 0.509; 95\% CI: 0.175-1.481; $\mathrm{P}=0.215$ ). Preoperative leg ischemia was a risk factor in the three groups, similar to preoperative myocardial ischemia, but not mesenteric ischemia. In the whole group and CI group, no open surgery was a strong risk factor for death (OR: 9.899, 95\% CI: 6.128-15.990; P=0.000; OR 7.330, 95\% CI: $2.758-$ 19.481, $\mathrm{P}=0.000$ ) (Figures 2,3,4).

\section{Characteristics of patients in the CC group and safe duration for CI patients}

Compared with the non-CC group, no differences were found in age, male sex, or BMI in the CC group. More patients had persistent CI in the CC group (40\% vs. $17.2 \%$; $\mathrm{P}=0.043)$, and coma patients accounted for a larger ratio in the CC group ( $40 \%$ vs. $7.5 \%$; $\mathrm{P}=0.001$ ). The time from symptom onset to hospital stay was significantly longer 
Table 1 Demographic and characteristics between CI and non-CI

\begin{tabular}{|c|c|c|c|}
\hline Characteristics & $\begin{array}{c}\mathrm{Cl} \\
(\mathrm{n}=131)\end{array}$ & $\begin{array}{c}\text { non-Cl } \\
(n=1,042)\end{array}$ & $P$ value \\
\hline Age, years & $56.3 \pm 13.4$ & $53.2 \pm 13.5$ & 0.013 \\
\hline Gender (male) & $91(69.5 \%)$ & $786(75.4 \%)$ & 0.139 \\
\hline BMI $\left(\mathrm{kg} / \mathrm{m}^{2}\right)$ & $24.8 \pm 4.4$ & $25.7 \pm 4.7$ & 0.033 \\
\hline Hours from onset to hospital & $8.4 \pm 6.0$ & $18.9 \pm 30.0$ & 0.000 \\
\hline Pain & $102(77.9 \%)$ & $983(94.4 \%)$ & 0.000 \\
\hline Chest pain & $98(75.4 \%)$ & $912(87.5 \%)$ & 0.000 \\
\hline Back pain & $40(30.8 \%)$ & $441(42.3 \%)$ & 0.012 \\
\hline Abdominal pain & $4(3.1 \%)$ & $63(6.0 \%)$ & 0.169 \\
\hline Leg pain & $3(2.3 \%)$ & $32(3.1 \%)$ & 0.630 \\
\hline Hypertension & $93(71.0 \%)$ & $774(74.3 \%)$ & 0.419 \\
\hline Marfan syndrome & $1(0.8 \%)$ & $26(2.5 \%)$ & 0.213 \\
\hline DM & $3(2.3 \%)$ & $38(3.6 \%)$ & 0.426 \\
\hline Aortic aneurysm history & $3(2.3 \%)$ & $14(1.3 \%)$ & 0.393 \\
\hline Aortic dissection history & $3(2.3 \%)$ & $24(2.3 \%)$ & 0.992 \\
\hline CABG history & $1(0.8 \%)$ & $0(0 \%)$ & 0.005 \\
\hline TEVAR history & $3(2.3 \%)$ & $25(2.4 \%)$ & 0.937 \\
\hline AVR history & $0(0 \%)$ & $8(0.8 \%)$ & 0.314 \\
\hline Stroke history & $5(3.8 \%)$ & $35(3.5 \%)$ & 0.786 \\
\hline CAD history & $6(4.6 \%)$ & $24(2.3 \%)$ & 0.120 \\
\hline COPD history & $2(1.5 \%)$ & $13(1.2 \%)$ & 0.789 \\
\hline AF history & $2(1.5 \%)$ & $10(1.0 \%)$ & 0.544 \\
\hline ESKD history & $2(1.5 \%)$ & $22(2.1 \%)$ & 0.656 \\
\hline Smoke & 19 (14.5\%) & $244(23.4 \%)$ & 0.021 \\
\hline Alcohol & $12(9.2 \%)$ & $160(15.4 \%)$ & 0.059 \\
\hline Limb ischemia & $22(16.8 \%)$ & 157 (15.1\%) & 0.605 \\
\hline Mesenteric ischemia & $10(7.6 \%)$ & $41(3.9 \%)$ & 0.051 \\
\hline Myocardial ischemia & $8(6.1 \%)$ & $44(4.2 \%)$ & 0.324 \\
\hline Hypotension & $18(13.7 \%)$ & $62(6.0 \%)$ & 0.000 \\
\hline Tamponade & $29(26.9 \%)$ & $102(10.4 \%)$ & 0.000 \\
\hline Type of Cl & & & - \\
\hline Transient & $103(78.6 \%)$ & - & \\
\hline Persistent & 22 (21.4\%) & - & \\
\hline Coma & $30(22.9 \%)$ & - & - \\
\hline Open surgery & $108(82.4 \%)$ & $984(94.4 \%)$ & 0.000 \\
\hline
\end{tabular}

Table 1 (continued)
Table 1 (continued)

\begin{tabular}{|c|c|c|c|}
\hline Characteristics & $\begin{array}{c}C l \\
(n=131)\end{array}$ & $\begin{array}{c}\text { non-Cl } \\
(n=1,042)\end{array}$ & $P$ value \\
\hline \multicolumn{4}{|l|}{ Root procedure } \\
\hline Bentall & $20(18.5 \%)$ & $209(21.2 \%)$ & 0.510 \\
\hline Root reconstruction & $86(79.6 \%)$ & $741(75.3 \%)$ & 0.320 \\
\hline VSRR & $1(0.9 \%)$ & $18(1.8 \%)$ & 0.496 \\
\hline Total arch replacement & $48(44.4 \%)$ & $467(47.5 \%)$ & 0.551 \\
\hline Cerebral perfusion & & & 0.540 \\
\hline No perfusion & $17(15.7 \%)$ & $125(12.8 \%)$ & \\
\hline ACP & $86(79.7 \%)$ & $804(82.0 \%)$ & \\
\hline $\mathrm{RCP}$ & $5(4.6 \%)$ & $51(5.2 \%)$ & \\
\hline CPB & $250.0 \pm 98.0$ & $239.0 \pm 73.4$ & 0.159 \\
\hline Clamp & $172.4 \pm 99.0$ & $166.2 \pm 55.5$ & 0.529 \\
\hline $\mathrm{HCA}$ & $28.8 \pm 8.9$ & $30.5 \pm 11.3$ & 0.073 \\
\hline Lowest temperature & $20.4 \pm 2.5$ & $20.8 \pm 2.4$ & 0.167 \\
\hline \multicolumn{4}{|l|}{$\begin{array}{l}\text { Postoperative } \\
\text { complications }\end{array}$} \\
\hline Cerebral complications & $8(7.4 \%)$ & $51(5.2 \%)$ & 0.333 \\
\hline Paraplegia & $5(4.6 \%)$ & $18(1.8 \%)$ & 0.055 \\
\hline ARF & $32(29.6 \%)$ & $307(31.2 \%)$ & 0.733 \\
\hline CRRT & $16(14.8 \%)$ & $111(11.3 \%)$ & 0.279 \\
\hline Re-exploration & $9(8.3 \%)$ & $54(5.5 \%)$ & 0.230 \\
\hline Mortality & $37(28.2 \%)$ & $166(15.9 \%)$ & 0.000 \\
\hline
\end{tabular}

$\mathrm{Cl}$, cerebral ischemia; $\mathrm{BMI}$, body mass index; DM, diabetes mellitus; CABG, coronary artery bypass graft; TEVAR, thoracic endovascular aortic repair; AVR, aortic valve replacement; CAD, coronary artery disease; COPD, chronic obstructive pulmonary disease; AF, atrial fibrillation; ESKD, end stage kidney disease; VSRR, valve sparing root replacement; $A C P$, antegrade cerebral perfusion; $R C P$, retrograde cerebral perfusion; $C P B$, cardiopulmonary bypass; HCA, hypothermic circulation arrest; ARF, acute renal failure; CRRT, continuously renal replacement therapy.

in the CC group $(13.6 \pm 9.8$ vs. $7.5 \pm 4.6$ hours; $\mathrm{P}=0.033)$, but more quickly from hospital to surgery $(2.1 \pm 1.1 \mathrm{vs}$. $3.2 \pm 2.3 ; \mathrm{P}=0.020)$. The strategies of artery cannulation, root procedures and cerebral perfusion were all similar. The ratios of conservative arch replacement (CAR) and total arch replacement (TAR) were the same, but the stent was more popular in the CC group (60\% vs. $32.3 \% ; \mathrm{P}=0.03)$. Patients in the CC group had a similar operation time, 


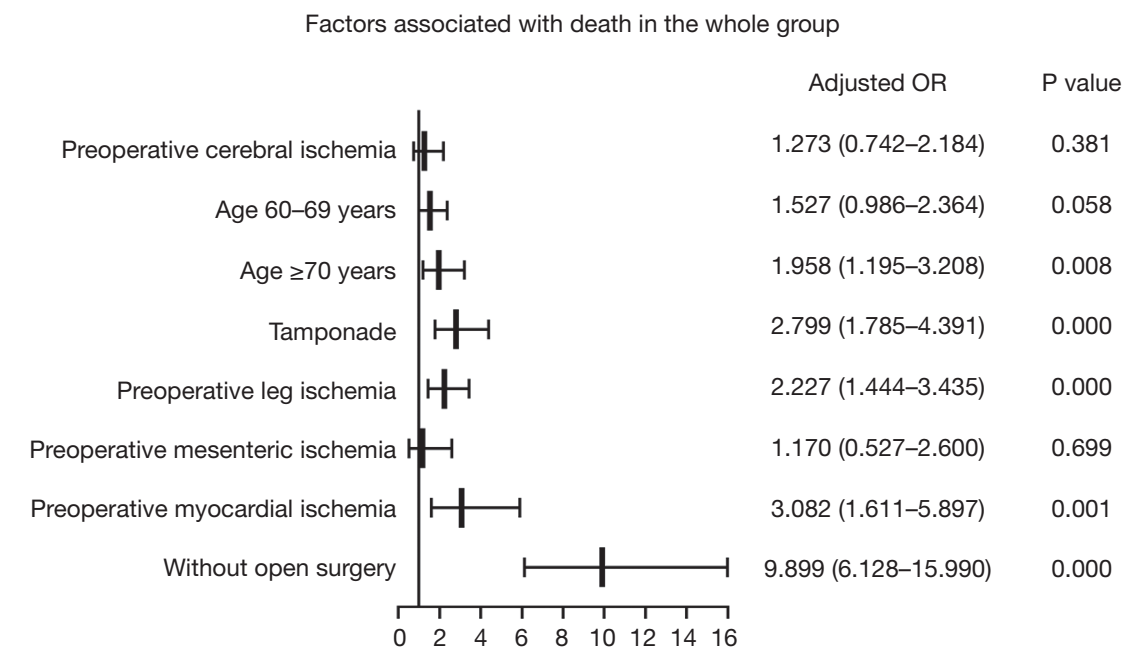

Figure 2 Multivariate analysis results to identify factors associated with death in the whole group.

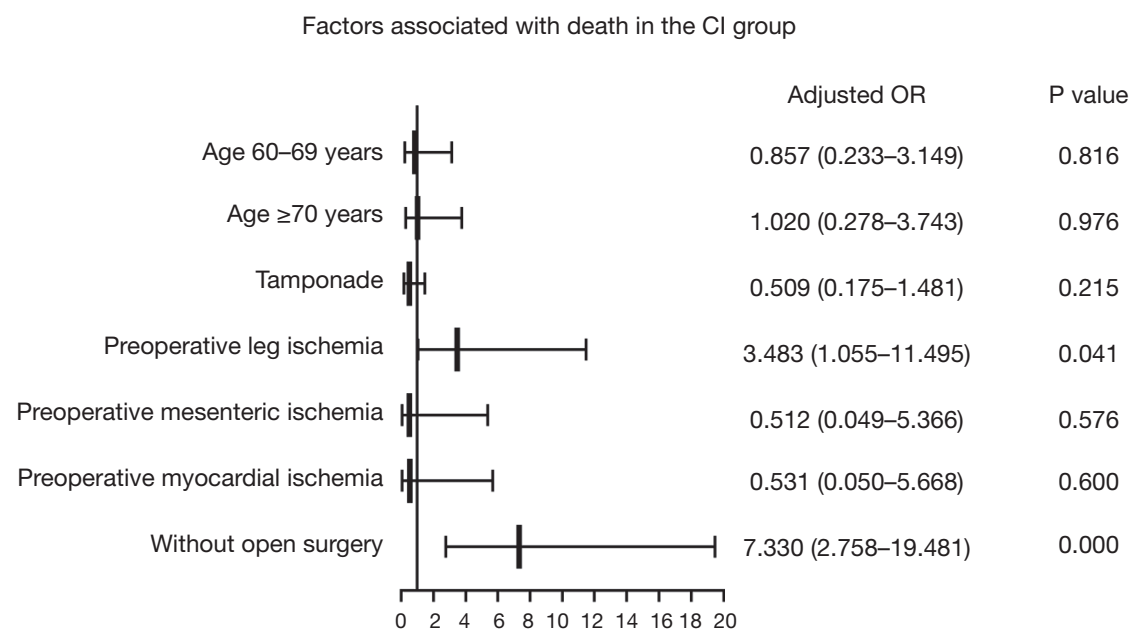

Figure 3 Multivariate analysis results to identify factors associated with death in the CI group.

$\mathrm{CPB}$ time, HCA time and mechanical ventilation time, as well as similar rates of complications of ARF, CRRT and re-exploration. The average time of ICU days and hospital days were also approximately the same. The 30-day mortality was higher in the CC group (46.7\% vs. $16.1 \%$; $\mathrm{P}=0.007$ ) (Table 2).

ROC curves were used to identify the cut-off point of the safe duration for preoperative CI patients receiving surgery without recovery from $\mathrm{CC}$ after central repair. The area under the curve was 0.55 for death as the end point $(\mathrm{P}=0.466)$ and 0.71 for a worse neurological outcome $(\mathrm{P}=0.011)$. The cut-off point for consistent CC was 12.75 hours, but the results were non-significant (sensitivity $73.3 \%$; specificity 31.2\%) (Figure 5).

\section{Discussion}

Although retrospective reviews from registered databases and single-center experiences have revealed the characteristics and outcomes of aTAAD patients with concomitant CI, we summarized and reported four important points from our center's results: (I) The baseline demographics and onset symptoms were different in the CI cohort; (II) central repair surgery is still effective; (III) the preoperative type of CI, coma status and the duration from CI onset to surgery were indicators for patients who did not recover after surgery; (IV) 


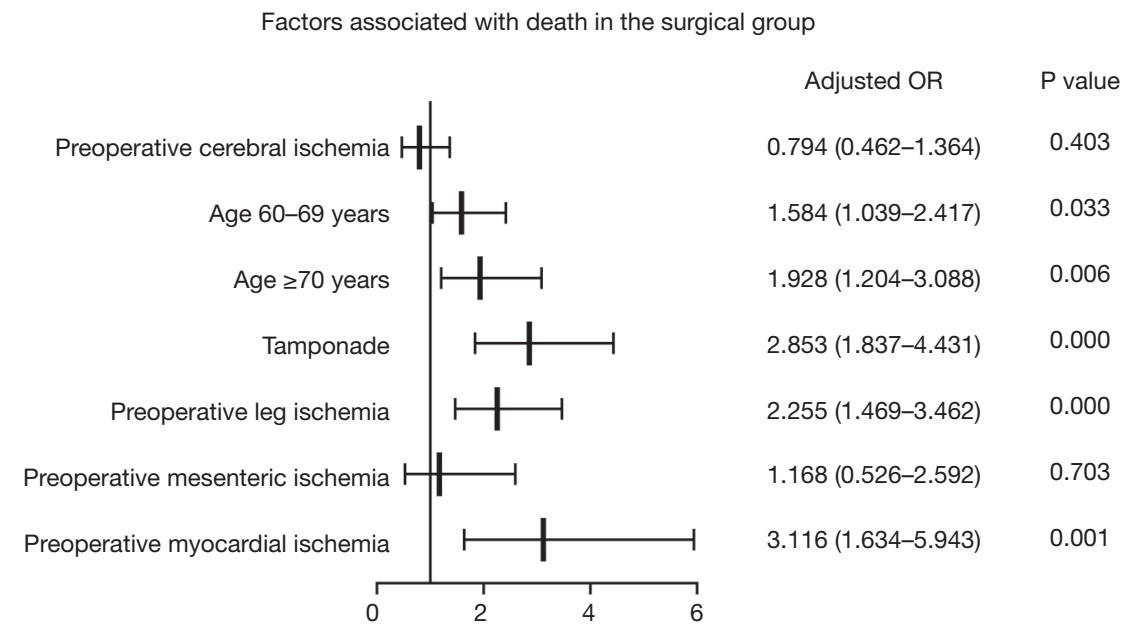

Figure 4 Multivariate analysis results to identify factors associated with death in the surgical group

Table 2 Comparison between CC and non-CC in CI surgical group

\begin{tabular}{|c|c|c|c|}
\hline Characteristics & $\begin{array}{c}\text { CC } \\
(n=15)\end{array}$ & $\begin{array}{c}\text { Non-CC } \\
(n=93)\end{array}$ & $P$ value \\
\hline Age, years & $57.8 \pm 10.5$ & $56.1 \pm 13.0$ & 0.637 \\
\hline Gender (male) & $91(69.5 \%)$ & $786(75.4 \%)$ & 0.277 \\
\hline BMI $\left(\mathrm{kg} / \mathrm{m}^{2}\right)$ & $23.6 \pm 3.6$ & $25.1 \pm 3.7$ & 0.140 \\
\hline Type of $\mathrm{Cl}$ & & & 0.043 \\
\hline Transient & $9(60 \%)$ & 77 (82.8\%) & \\
\hline Persistent & $6(40 \%)$ & $16(17.2 \%)$ & \\
\hline Coma status & $6(40 \%)$ & $7(7.5 \%)$ & 0.001 \\
\hline Hours from onset to hospital & $13.6 \pm 9.8$ & $7.5 \pm 4.6$ & 0.033 \\
\hline Hours from hospital to surgery & $2.1 \pm 1.1$ & $3.2 \pm 2.3$ & 0.020 \\
\hline Hours from onset to surgery & $15.9 \pm 10.2$ & $10.7 \pm 4.9$ & 0.073 \\
\hline \multicolumn{4}{|l|}{ Cannulation } \\
\hline Axillary artery & $2(13.3 \%)$ & $19(20.4 \%)$ & 0.521 \\
\hline Femoral artery & $5(33.3 \%)$ & $23(24.7 \%)$ & 0.483 \\
\hline Axillary + femoral artery & $8(53.3 \%)$ & $51(54.8 \%)$ & 0.914 \\
\hline \multicolumn{4}{|l|}{ Root procedure } \\
\hline Bentall & $1(6.7 \%)$ & $19(20.4 \%)$ & 0.205 \\
\hline Root reconstruction & $14(93.3 \%)$ & $72(77.4 \%)$ & 0.158 \\
\hline \multicolumn{4}{|l|}{ Arch procedure } \\
\hline CAR & 2 (13.3\%) & 18 (19.4\%) & 0.579 \\
\hline TAR & $4(26.7 \%)$ & 44 (47.3\%) & 0.137 \\
\hline
\end{tabular}

Table 2 (continued)
Table 2 (continued)

\begin{tabular}{|c|c|c|c|}
\hline Characteristics & $\begin{array}{c}C C \\
(n=15)\end{array}$ & $\begin{array}{c}\text { Non-CC } \\
(n=93)\end{array}$ & $P$ value \\
\hline Stent & $9(60 \%)$ & $30(32.3 \%)$ & 0.039 \\
\hline Cerebral perfusion & & & 0.141 \\
\hline Without perfusion & $4(26.7 \%)$ & $13(14.0 \%)$ & \\
\hline ACP & $11(73.3 \%)$ & 75 (80.6\%) & \\
\hline $\mathrm{RCP}$ & $0(0 \%)$ & $5(5.4 \%)$ & \\
\hline Operation time (hours) & $8.3 \pm 3.4$ & $8.1 \pm 1.7$ & 0.892 \\
\hline CPB (min) & $222.6 \pm 51.0$ & $254.1 \pm 102.8$ & 0.263 \\
\hline Clamp & $152.1 \pm 58.0$ & $175.4 \pm 103.7$ & 0.413 \\
\hline $\mathrm{HCA}$ & $27.7 \pm 10.3$ & $29.0 \pm 8.7$ & 0.605 \\
\hline MV & $82.3 \pm 69.0$ & $61.4 \pm 70.0$ & 0.374 \\
\hline ARF & $3(20 \%)$ & $29(31.2 \%)$ & 0.381 \\
\hline CRRT & $3(20 \%)$ & $13(14 \%)$ & 0.544 \\
\hline Re-exploration & $0(0 \%)$ & $9(9.7 \%)$ & 0.210 \\
\hline ICU days & $9.3 \pm 8.3$ & $7.7 \pm 7.2$ & 0.470 \\
\hline Hospital days & $19.8 \pm 19.3$ & $20.9 \pm 10.9$ & 0.772 \\
\hline 30-day mortality & $7(46.7 \%)$ & $15(16.1 \%)$ & 0.007 \\
\hline
\end{tabular}

$\mathrm{CC}$, cerebral complication; $\mathrm{Cl}$, cerebral ischemia; $\mathrm{BMI}$, body mass index; CAR, conservative arch replacement; TAR, total arch replacement; $A C P$, antegrade cerebral perfusion; RCP, retrograde cerebral perfusion; $\mathrm{CPB}$, cardiopulmonary bypass; HCA, hypothermic circulation arrest; MV, mechanical ventilation; ARF, acute renal failure; CRRT, continuously renal replacement therapy; ICU, intensive care unit. 

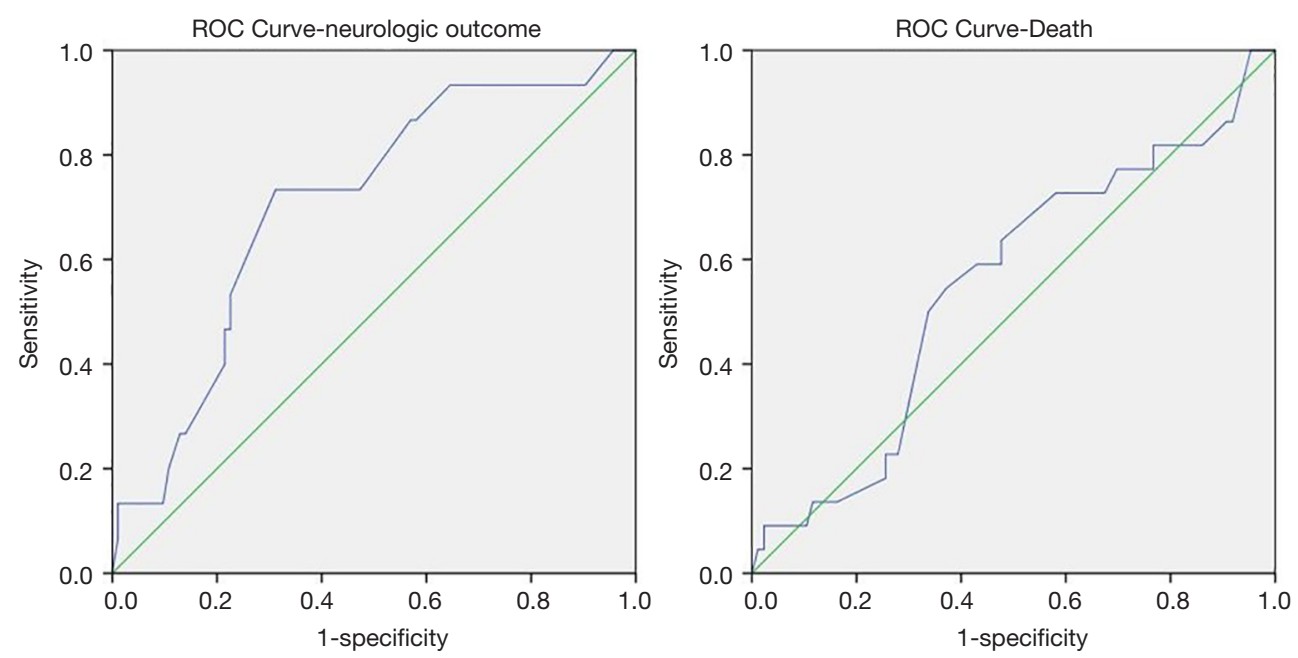

Figure 5 ROC curve to identify correlation of time-operation and outcomes of neurologic status and death.

12.75 hours seemed to be the safe duration for patients with aTAAD concomitant with CI.

\section{Prevalence, characteristics, and outcomes}

The latest series report from IRAD introduced by Sultan et al. had revealed that nearly $15 \%$ of patients with aTAAD present with CI. The definition of CI in this article was that 'clinical presentation at the time of aTAAD with clear evidence of neurologic deficit on physical exam' (1). The prevalence rate was higher than that in two previous reports from IRAD in 2013, and the rate of stroke in one series was $6.0 \%$, which was defined as cerebrovascular accidents representing a loss of neurological function and confirmed by CT or MRI (2). Another report found that the rate of cerebrovascular accidents was $4.7 \%$, and the rate of coma was $2.9 \%$ (3). Given the limited number of single-center experiences, the results were all consistent depending on the definition of CI, the prevalence of CI was 10.6-25.3\%, and the mortality for CI patients was $18.8-43.7 \%$ (7-9).

Patients with CI had obviously different at baseline characteristics and manifestations. In our study, patients with CI were older (average age: 56.3 years), but still much younger than those reported in other studies (average age: 62.1-65.0 years). Younger age at presentation with aTAAD is a remarkable phenomenon from a database research from China and was 51.8 years from Sino-RAD (10). The pain symptoms were common in patients with CI, with $75.4 \%$ chest pain and $30.8 \%$ back pain in our series, compared with $66.0 \%$ chest pain and $35.9 \%$ back pain in another report. A lower ratio of pain symptoms leads to a higher rate of misdiagnosis and delayed diagnosis, which would aggravate CI because of untimely diagnosis and treatment. Simultaneously, CI is often associated with the malperfusion of other organs, the most important cause of death (11-13). An insufficient intracranial blood supply due to carotid dissection may be the cause of CI and includes blockage of the endometrial membranes, and intracranial arterial thrombosis caused by blood stasis (14). Part of the former may be relieved by CI symptoms because of blood flow perfusion, and the latter is more likely to form persistent stroke. These events will lead to atypical symptoms of aTAAD that cannot be distinguished from stroke. Therefore, the initial diagnosis of patients with symptoms of CI is particularly important. At our hospital, the current practice is to perform cerebral CTA including aortic arch levels at the same time in patients with CI symptoms, particularly those without chest and back pain.

\section{Strategy for aTAAD patients with CI}

Based on IRAD results, $24 \%$ of patients with CVA and $33 \%$ of patients with coma had not received surgery, compared with $11 \%$ of patients without CI (3). In our series, $17.6 \%$ from the CI group and 5.6\% from the non-CI group had not received surgery. For 81 patients without surgery, accounting for $6.9 \%(81 / 1,173)$ of all patients, CI was one of the main reasons (28.4\%). Unfortunately, medical therapy for CI patients had worse outcomes than surgery therapy; the mortality was $100 \%$ for coma patients and $76.2 \%$ for 
stroke patients, and surgery was found to be a protective factor (OR: 0.058; $\mathrm{P}<0.001)(3)$. The analysis results from our series also confirmed that not receiving surgery was a strong risk factor for death in both the whole group (OR: 9.899; $\mathrm{P}=0.000)$ and $\mathrm{CI}$ group (OR: 7.330; $\mathrm{P}=0.000)$. In the surgical group, CI was not a risk factor for death, revealing that central repair surgery is still effective for CI patients.

Because surgery is effective for CI patients, a strategy including indicators for surgery and the timing and methods for surgery is necessary. In our series, 103 patients had transient CI, indicating that the symptoms and signs of $\mathrm{CI}$ had recovered before surgery, and the other 22 patients presented with persistent CI symptoms. The transient type is a sign of recovery from perfusing cerebral blood flow, and the underlying mechanism is that the vessel dissection involvement opens again. Blockage due to the intimal membrane is dynamic, and the time prolonged is not so long to induce irreversible cerebral damage. According to Orihashi et al., which described perfusion patterns, the transient type may correspond to type B (15). Among surgical patients, the CI type predicts cerebral function recovery after surgery. A total of $10.5 \%$ of the transient type and $27.3 \%$ of the persistent type had postoperative CC, and the results from IRAD were $18.2 \%$ of the transient ischemic attack cohort and $50 \%$ of the stroke type (2). Hence, transient-type patients could receive immediate central repair surgery with similar cerebral outcomes as those without CI $(16,17)$.

Additionally, preoperative coma, which is induced by local CI with persistent vessel obstruction (excluding cases with global ischemia due to preoperative hypotension, shock and/ or tamponade), is a predictor for adverse outcomes $(9,18-20)$. Hiroshi Tanaka et al. suggested that coma in patients for more than 3 hours after onset was a contraindication for central repair surgery, and revascularization of the dissected vessels by carotid stenting or other methods was recommended (9). Another small sample group with five comatose and hemodynamically stable patients had undergone central repair surgery for less than 12 hours and had satisfactory outcomes (no death and stroke) (21). Based on the medical level and referral system in China, it is difficult to achieve emergency surgery within 3 hours. In particular, in our group of CI patients, the duration was 15 hours from onset to admission. Therefore, our recommendation is to adopt a reperfusion-first strategy for all patients with coma. This strategy has been implemented since 2019. Cerebral angiography and stent implantation were performed on 3 preoperative coma patients. One patient recovered and received central repair surgery and recovered well; and the other two patients remained unconscious and no further surgery was performed.

According to the above, the duration from CI onset to surgery can affect the outcomes. The operation time indirectly represents the time to restore cerebral blood flow perfusion, and it still depends on the time from the start of the surgery to the restoration of cerebral blood flow. Regardless of how it defined, the safe time duration reported by different centers ranges from 3 to 9 hours (7-9). Another study by Peter Chiu et al. found no correlation between the operation time and outcomes, as reflected by the a poor values of both neurologic outcomes (area under the curve, 0.40) and death (area under the curve, 0.49) (8). We also checked the correlation of the time-operation and the outcomes of neurologic status and death, and the results showed that the areas under the curve was 0.72 and 0.55 , respectively. The cut-off point for neurologic outcome was 12.75 hours. Based on clinical experience in neurology, 3 hours was used as the time treatment window for thrombolysis (22). With the progression of the endovascular treatment of cerebral vessel occlusion, the windows now extend to 6 hours, and recent trials also suggest that this could increase further to 24 hours $(23,24)$. Thus, we chose 12.75 hours as a time point for CI patients. CI patients with a time duration longer than 12.75 hours should receive reperfusion-first therapy. Thrombolysis using intravenous tissue plasminogen activator is a traditional method, but the safety and effectiveness of endovascular treatment promote the strategy for CI.

\section{Limitations}

Our study has several limitations. First, it was a retrospective analysis at a single center. Second, cranial CT was not available for every aTAAD patient with CI, likely resulting in the loss of some patients with CI but no manifestation. Finally, the included time span is large, and we have different changes in the surgical method and intraoperative treatment of aTAAD. It is difficult to separate them to analyze the impact on the outcomes of CI patients.

\section{Conclusions}

Prompt surgery is still effective for aTAAD with CI. For patients with the transient type, immediate surgery is recommended regardless of the length of duration. For comatose patients and persistent type patients with 
a duration longer than 12.75 hours, the application of a reperfusion-first strategy with endovascular treatment could reduce the worse neurologic outcomes.

\section{Acknowledgments}

Funding: This work has been supported by the National Natural Science Foundation of China (No. 81970401, 81670437) and Jiangsu Provincial Key Medical Discipline (ZDXKA2016019).

\section{Footnote}

Reporting Checklist: The authors have completed the STROBE reporting checklist. Available at http://dx.doi. org/10.21037/jtd-20-2349

Data Sharing Statement: Available at http://dx.doi. org/10.21037/jtd-20-2349

Peer Review File: Available at http://dx.doi.org/10.21037/jtd20-2349

Conflicts of Interest: All authors have completed the ICMJE uniform disclosure form (available at http://dx.doi. org/10.21037/jtd-20-2349). The authors have no conflicts of interest to declare.

Ethical Statement: The authors are accountable for all aspects of the work in ensuring that questions related to the accuracy or integrity of any part of the work are appropriately investigated and resolved. The study was conducted in accordance with the Declaration of Helsinki (as revised in 2013). The current study was approved by the institutional review board of Nanjing Drum Tower Hospital (2020-185-01) and patient consent was waived due to the retrospective nature of this study.

Open Access Statement: This is an Open Access article distributed in accordance with the Creative Commons Attribution-NonCommercial-NoDerivs 4.0 International License (CC BY-NC-ND 4.0), which permits the noncommercial replication and distribution of the article with the strict proviso that no changes or edits are made and the original work is properly cited (including links to both the formal publication through the relevant DOI and the license). See: https://creativecommons.org/licenses/by-nc-nd/4.0/.

\section{References}

1. Sultan I, Bianco V, Patel HJ, et al. Surgery for type A aortic dissection in patients with cerebral malperfusion: Results from the International Registry of Acute Aortic Dissection. J Thorac Cardiovasc Surg 2019. [Epub ahead of print]. doi: 10.1016/j.jtcvs.2019.11.003.

2. Bossone E, Corteville DC, Harris KM, et al. Stroke and outcomes in patients with acute type A aortic dissection. Circulation 2013;128:S175-9.

3. Di Eusanio M, Patel HJ, Nienaber CA, et al. Patients with type A acute aortic dissection presenting with major brain injury: should we operate on them? J Thorac Cardiovasc Surg 2013;145:S213-21.e1.

4. Pan J, Li QG, Zhou Q, et al. Repair of acute type A aortic dissections using open replacement with triple-branched stent grafts. Ann Thorac Surg 2013;96:559-62.

5. Zhou Q, Xue Y, Cao H, et al. Novel arch fenestrated stent graft for acute Stanford Type A aortic dissection with open antegrade implantation. Interact Cardiovasc Thorac Surg 2018;26:369-75.

6. Xue Y, Zhou Q, Pan J, et al. Root reconstruction for proximal repair in acute type A aortic dissection. J Thorac Dis 2019;11:4708-16.

7. Estrera AL, Garami Z, Miller CC, et al. Acute type A aortic dissection complicated by stroke: can immediate repair be performed safely? J Thorac Cardiovasc Surg 2006;132:1404-8.

8. Chiu P, Rotto TJ, Goldstone AB, et al. Time-to-operation does not predict outcome in acute type $\mathrm{A}$ aortic dissection complicated by neurologic injury at presentation. J Thorac Cardiovasc Surg 2019;158:665-72.

9. Tanaka H, Okada K, Yamashita T, et al. Surgical results of acute aortic dissection complicated with cerebral malperfusion. Ann Thorac Surg 2005;80:72-6.

10. Wang W, Duan W, Xue Y, et al. Clinical features of acute aortic dissection from the Registry of Aortic Dissection in China. J Thorac Cardiovasc Surg 2014;148:2995-3000.

11. Narayan P, Rogers CA, Benedetto U, et al. Malperfusion rather than merely timing of operative repair determines early and late outcome in type A aortic dissection. J Thorac Cardiovasc Surg 2017;154:81-6.

12. Conzelmann LO, Weigang E, Mehlhorn U, et al. Mortality in patients with acute aortic dissection type A: analysis of pre- and intraoperative risk factors from the German Registry for Acute Aortic Dissection Type A (GERAADA). Eur J Cardiothorac Surg 2016;49:e44-52. 
13. Czerny M, Schoenhoff F, Etz C, et al. The Impact of PreOperative Malperfusion on Outcome in Acute Type A Aortic Dissection: Results From the GERAADA Registry. J Am Coll Cardiol 2015;65:2628-35.

14. Berretta P, Trimarchi S, Patel HJ, et al. Malperfusion syndromes in type A aortic dissection: what we have learned from IRAD. J Vis Surg 2018;4:65.

15. Orihashi K, Sueda T, Okada K, Imai K. Perioperative diagnosis of mesenteric ischemia in acute aortic dissection by transesophageal echocardiography. Eur J Cardiothorac Surg 2005;28:871-6.

16. Dumfarth J, Kofler M, Stastny L, et al. Stroke after emergent surgery for acute type A aortic dissection: predictors, outcome and neurological recovery. Eur J Cardiothorac Surg 2018;53:1013-20.

17. Ghoreishi M, Sundt TM, Cameron DE, et al. Factors associated with acute stroke after type A aortic dissection repair: An analysis of the Society of Thoracic Surgeons National Adult Cardiac Surgery Database. J Thorac Cardiovasc Surg 2020;159:2143-54.e3.

18. Morimoto N, Okada K, Okita Y. Lack of neurologic improvement after aortic repair for acute type A aortic dissection complicated by cerebral malperfusion: predictors and association with survival. J Thorac Cardiovasc Surg

Cite this article as: Xue Y, Tang X, Zhu X, Lu Y, Zhang H, Xie W, Zhou Q, Wang D. Prompt surgery is effective for acute type A aortic dissection with cerebral ischemia. J Thorac Dis 2021;13(3):1403-1412. doi: 10.21037/jtd-20-2349
2011;142:1540-4.

19. Tsukube T, Hayashi T, Kawahira T, et al. Neurological outcomes after immediate aortic repair for acute type A aortic dissection complicated by coma. Circulation 2011;124:S163-7.

20. Tsukube T, Haraguchi T, Okada Y, et al. Long-term outcomes after immediate aortic repair for acute type A aortic dissection complicated by coma. J Thorac Cardiovasc Surg 2014;148:1013-8; discussion 1018-9.

21. Pocar M, Passolunghi D, Moneta A, et al. Coma might not preclude emergency operation in acute aortic dissection. Ann Thorac Surg 2006;81:1348-51.

22. Hacke W, Kaste M, Bluhmki E, et al. Thrombolysis with alteplase 3 to 4.5 hours after acute ischemic stroke. N Engl J Med 2008;359:1317-29.

23. Albers GW, Lansberg MG, Kemp S, et al. A multicenter randomized controlled trial of endovascular therapy following imaging evaluation for ischemic stroke (DEFUSE 3). Int J Stroke 2017;12:896-905.

24. Jovin TG, Saver JL, Ribo M, et al. Diffusion-weighted imaging or computerized tomography perfusion assessment with clinical mismatch in the triage of wake up and late presenting strokes undergoing neurointervention with Trevo (DAWN) trial methods. Int J Stroke 2017;12:641-52. 